\title{
SIMPLE AND RAPID LIQUID CHROMATOGRAPHY METHOD FOR SIMULTANEOUS DETERMINATION OF ISONIAZID AND PYRAZINAMIDE IN PLASMA
}

\author{
Hemanth Kumar AK, Sudha V, Ramachandran G
}

National Institute for Research in Tuberculosis, Chetput, Chennai, India

\begin{abstract}
Introduction: Treatment of tuberculosis (TB) requires a combination of drugs. Isoniazid (INH) and pyrazinamide (PZA) are key components of the first-line regimen used in the treatment of TB and monitoring these drug levels in plasma would help in better patient care. The objective of the study is to develop and validate a simple and rapid high performance liquid chromatographic method for simultaneous determination of INH and PZA in human plasma.

Methodology: The method involved deproteinisation of plasma with para hydroxy benzaldehyde and trifluoroacetic acid and analysis using a reversed-phase $C^{8}$ column and UV detection at $267 \mathrm{~nm}$. The flow rate was set at $1.5 \mathrm{ml} / \mathrm{min}$ at ambient temperature. The accuracy, linearity, precision, specificity, stability and recovery of the method were evaluated. The method was applied to estimate plasma INH and PZA collected from six children with TB.

Results: Well resolved peaks of PZA and INH at retention times of 3.2 and 6.1 minutes respectively were obtained. The assay was linear from $0.25-10.0 \mu \mathrm{g} / \mathrm{ml}$ for INH and $1.25-50.0 \mu \mathrm{g} / \mathrm{ml}$ for PZA. The within-day and between-day relative standard deviation for standards were below $10 \%$. The average recoveries of INH and PZA from plasma were 104 and 102\% respectively.

Conclusions: A rapid and accurate method for simultaneous determination of INH and PZA in plasma was validated. The assay spans the concentration range of clinical interest. The easy sample preparation and small sample size makes this assay highly suitable for pharmacokinetic studies of INH and PZA in TB patients.
\end{abstract}

Key words: Isoniazid, Pyrazinamide, Plasma, HPLC

\section{INTRODUCTION}

Treatment of pulmonary and extra pulmonary tuberculosis (TB) consists of a 6-month short course chemotherapy regimen with isoniazid $(\mathrm{INH})$, rifampicin (RMP), pyrazinamide (PZA) and ethambutol (EMB) for two months followed by INH

\section{Correspondence:}

Dr. Geetha Ramachandran

Scientist 'C

Dept. of Biochemistry \& Clinical Pharmacology

Tuberculosis Research Centre

Mayor V. R. Ramanathan Road

Chetput, Chennai - 600 031, India. and RMP for the next four months. It has been suggested that drug concentration measurements in TB patients with sub-optimal response to directly observed therapy may be necessary. ${ }^{1,2}$ Um et al have reported that low concentrations of anti-TB drugs are common, and therapeutic drug monitoring would be useful to optimise drug dosages, especially in patients with an inadequate clinical response to anti-TB treatment. ${ }^{3}$ Substantial inter-patient variability of anti-TB drug concentrations has been reported. ${ }^{4}$ Several factors are known to influence drug levels. ${ }^{4,5} \mathrm{INH}$ and PZA are key components of the first-line regimen used in the treatment of TB and monitoring these drug 
levels in plasma would help in better patient care.

Several methods to estimate INH and PZA by high performance liquid chromatography (HPLC) individually and in combination have been described. ${ }^{6-13}$ Song et al have described a method for simultaneous determination of RMP, INH, PZA and EMB by LC-MS-MS. ${ }^{14}$ There are also methods reported for simultaneous determination of RMP, INH and PZA by HPLC, which employ cumbersome solid phase extraction procedures ${ }^{12}$ or derivatisation prior to separation. ${ }^{13}$ The aim of this study was to develop and validate a simple and rapid assay for simultaneous estimation of $\mathrm{INH}$ and PZA in plasma by HPLC.

\section{METHODOLOGY}

\section{Chemicals}

Pure INH and PZA powder were obtained from Sigma Chemical Company, St.Louis, MO, USA. Methanol (HPLC grade), perchloric acid, tetrabutyl n-ammonium hydroxide, para hydroxy benzaldehyde and trifluoro acetic acid were purchased from Qualigens (India). Deionized water was processed through a Milli-Q water purification system (Millipore, USA). Pooled human plasma was obtained from a Blood Bank, Chennai, India.

\section{Chromatographic System}

The HPLC system (Shimadzu Corporation, Kyoto, Japan) consisted of two pumps (LC-10ATvp), diode array detector (SPD-M10Avp) and auto sampler (SIL-HTA) with built in system controller (SCL-10Avp). ClassVP-LC workstation was used for data collection and acquisition. The analytical column was a $\mathrm{C}_{8}, 250 \times 4.6 \mathrm{~mm} \mathrm{ID}, 5 \mathrm{~m}$ particle size protected by a compatible guard column (Lichrospher 100 RP-8e, Merck, Germany).

The mobile phase consisted of water: methanol $(80: 20 \mathrm{v} / \mathrm{v})$ containing $0.05 \%$ perchloric acid and $0.1 \%$ tetrabutyl $n$-ammonium hydroxide. Prior to preparation of the mobile phase, the solvents were degassed separately using a Millipore vacuum pump. The UV detector was set at 267 $\mathrm{nm}$. The chromatogram was run for 8 minutes at a flow rate of $1.5 \mathrm{ml} / \mathrm{min}$ at ambient temperature.
Unknown concentrations were derived from linear regression analysis of the peak height of analyte vs. concentration curve. The linearity was verified using estimates of correlation coefficient ( $r$ ).

\section{Preparation of standard solution}

Stock standards $(1 \mathrm{mg} / \mathrm{ml})$ of $\mathrm{INH}$ and PZA were prepared separately by dissolving the drugs in deionised water. The working standards of $I N H$ $(0.25$ to $10.0 \mu \mathrm{g} / \mathrm{ml})$ and PZA (1.25 to $50.0 \mu \mathrm{g} / \mathrm{ml})$ in combination were prepared in human plasma that was obtained from a Blood bank. Working standard solutions in human plasma containing $\mathrm{INH}$ and PZA respectively in the following concentrations were prepared: $0.25 \& 1.25 \mu \mathrm{g} / \mathrm{ml}, 0.5 \& 2.5 \mu \mathrm{g} / \mathrm{ml}$, $1.0 \& 5.0 \mu \mathrm{g} / \mathrm{ml}, 2.5 \& 12.5 \mu \mathrm{g} / \mathrm{ml} ; 5.0 \& 25.0 \mu \mathrm{g} / \mathrm{ml}$; $10.0 \& 50.0 \mu \mathrm{g} / \mathrm{ml}$.

\section{Sample preparation}

To $100 \mu \mathrm{l}$ each of calibration standards and test samples, $50 \mu$ l of para hydroxy benzaldehyde and $100 \mu \mathrm{l}$ of trifluoro acetic acid were added for deproteinisation and extraction of analytes. The

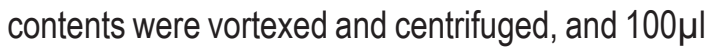
of the clear supernatant was injected into the HPLC column.

\section{Accuracy and Linearity}

The accuracy and linearity of INH and PZA standards were evaluated by analysing a set of standards ranging from 0.25 to $10.0 \mu \mathrm{g} / \mathrm{ml}$ for $\mathrm{INH}$ and 1.25 to $50.0 \mu \mathrm{g} / \mathrm{ml}$ for PZA. The within day and between day variations were determined by processing each standard concentration in duplicate for six consecutive days.

\section{Precision}

In order to evaluate the precision of the method, three different plasma samples from patients containing $\mathrm{INH}$ and PZA were processed and analysed in duplicate on three consecutive days.

\section{Recovery}

For the recovery experiment, plasma samples from two patients containing INH and PZA were spiked with 2.5 and $5.0 \mu \mathrm{g} / \mathrm{ml}$ of $\mathrm{INH}$ and 5.0 and $10.0 \mu \mathrm{g} /$ 
$\mathrm{ml}$ of PZA and assayed. The percentage of recovery was calculated by dividing sample differences with the added concentrations. Recovery experiments were carried out on three different occasions.

\section{Specificity}

Interference from endogenous compounds was investigated by analysing blank plasma samples obtained from six each of male and female subjects. Interference from certain anti-TB drugs, namely, RMP and EMB at a high concentration of $50 \mu \mathrm{g} / \mathrm{ml}$ was evaluated.

\section{Samples}

Six children with TB ( 3 males and 3 females) aged 4 to 11 years and body weight ranging from 13 to $38 \mathrm{~kg}$, who were attending the out-patient clinic of the centre, took part in the study. They were on regular anti-TB treatment consisting of INH, RMP, PZA and EMB thrice weekly for a period of 15 days to 2 months. On the study day, the patients were instructed to report to the clinic in a fasting condition. Blood samples $(2 \mathrm{ml})$ were drawn in heparinized vacutainer tubes before dosing and at 2, 4, 6 and 8 hours after dosing. All the blood samples were centrifuged immediately and plasma was separated and stored at $-20^{\circ} \mathrm{C}$ until assay. Estimations of plasma INH and PZA in all the samples were undertaken within 24 to 48 hours of blood collection. Informed written consent was obtained from all the parent/guardian of the children before blood draws were made.

\section{Stability}

The stability of INH and PZA in human plasma when stored at $-20^{\circ} \mathrm{C}$ was evaluated by assaying five plasma samples containing INH and PZA on days 1 and 30 .

\section{RESULTS AND DISCUSSION}

Treatment of TB usually involves a combination of drugs; hence a simple and accurate method for simultaneous estimation of some of the antiTB drugs is described. In this study, we have attempted to develop and validate a simple method, which requires a simple one-step deproteinisation method and analysis using a C8 column and an isocratic mobile phase. The present method has the advantages of being rapid (run time is only 8 minutes) and using a small sample volume (100 microlitres), without any loss of analytes.

Under the chromatographic conditions described above, INH and PZA were well separated as seen in the representative chromatograms (Figures 1a, b). The retention times of PZA and INH were 3.2 and 6.1 minutes respectively. Blank plasma samples did not give any peak at the retention times of $\mathrm{INH}$ and PZA (Figure 1c). The lowest concentrations of INH and PZA gave discrete peaks at the respective retention times (Figure 1a).

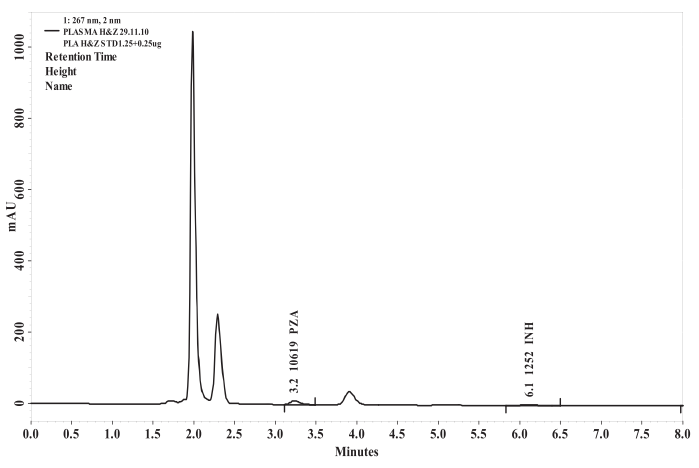

Figure 1a. Chromatogram of extracted isoniazid $(0.25 \mu \mathrm{g} /$ $\mathrm{ml})$ and pyrazinamide $(1.25 \mu \mathrm{g} / \mathrm{ml})$ plasma standards

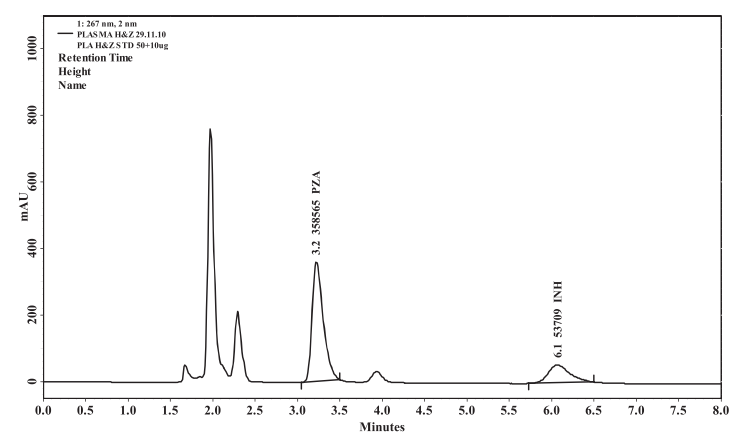

Figure 1b. Chromatogram of extracted isoniazid $(10.0 \mu \mathrm{g} /$ $\mathrm{ml})$ and pyrazinamide $(50.0 \mu \mathrm{g} / \mathrm{ml})$ plasma standards

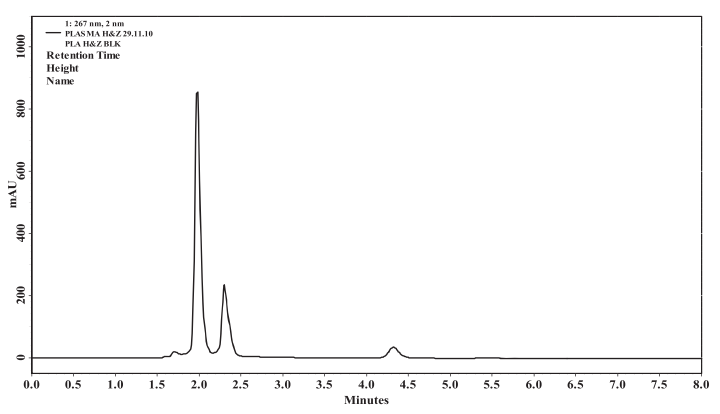

Figure 1c. Chromatogram of extracted blank plasma 
INH and PZA are used in the treatment of TB along with other first-line anti-TB drugs. Since not much is known about the interference of other drugs in the assay, it becomes necessary to rule out interference of anti-TB drugs in the assay of $\mathrm{INH}$ and PZA and establish the specificity of the method. No endogenous substances or first-line anti-TB drugs such as RMP and EMB interfered with the INH and PZA chromatograms.

$\mathrm{INH}$ and PZA concentrations ranging from 0.25 - $10.0 \mu \mathrm{g} / \mathrm{ml}$ and $1.25-50.0 \mu \mathrm{g} / \mathrm{ml}$ respectively were checked for linearity These concentrations span the range of clinical interest, which are reported to be present in plasma following treatment with INH and PZA. The calibration curve parameters of $\mathrm{INH}$ and PZA from six individual experiments for standard concentrations showed a linear relationship between peak height and concentrations, as evidenced by mean $( \pm$ SD) correlation coefficient values of $0.9995 \pm 0.0006$ and $0.9968 \pm 0.0014$ for INH and PZA respectively. The linearity and reproducibility of the various standards used for constructing calibration graphs for plasma INH and PZA are given in Table 1. The within-day and between-day relative standard deviation (RSD) for standards containing 0.25 to $10.0 \mu \mathrm{g} / \mathrm{ml}$ for $\mathrm{INH}$ ranged from 3.1 to $8.7 \%$ and 4.5 to $9.2 \%$ respectively, while the corresponding values for PZA standards containing 1.25 to $50.0 \mu \mathrm{g} / \mathrm{ml}$ ranged from 1.1 to $2.9 \%$ and 2.1 and $7.0 \%$ respectively.

The reproducibility of the method was further evaluated by analysing three plasma samples containing different concentrations of $\mathrm{INH}$ and PZA. The RSD for these samples ranged from 0.7 to $3.2 \%$ for INH and 6.2 to $7.6 \%$ for PZA. The $\%$ variations from the actual concentrations ranged from 96 to $101 \%$ for INH and 98 to $102 \%$ for PZA. For the concentration to be accepted as the lower limit of quantitation (LOQ), the RSD has to be less than $20 \%{ }^{15}$

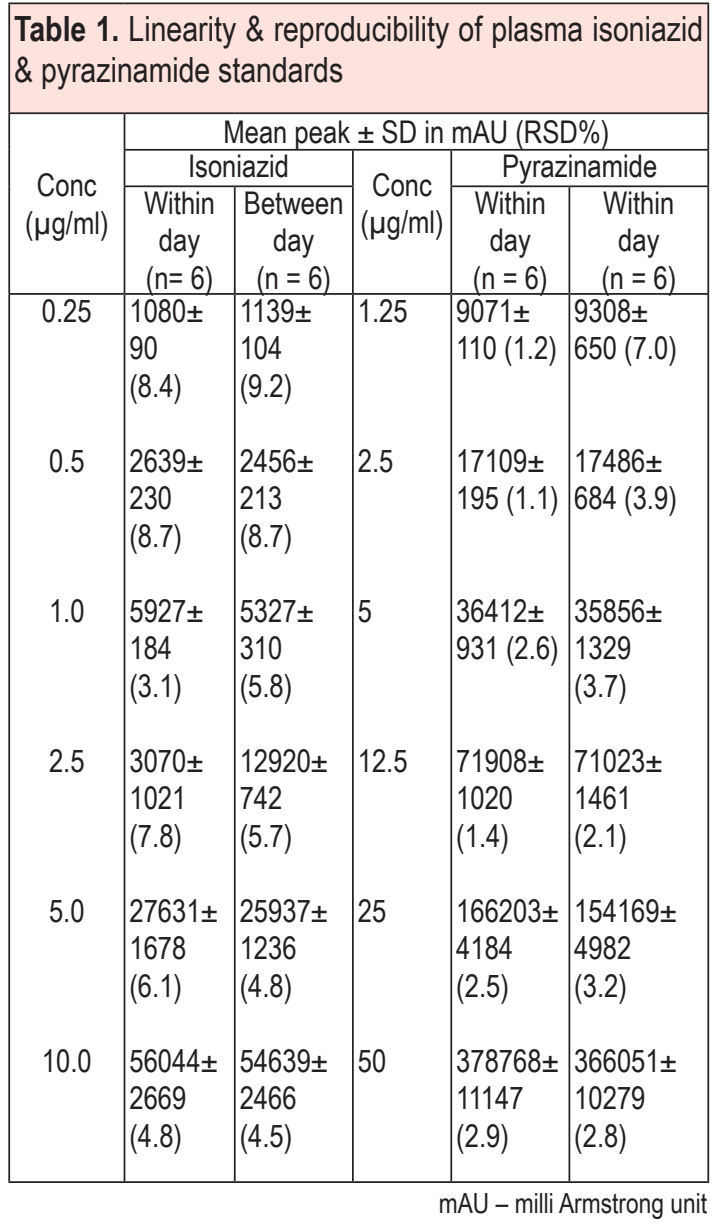

In the present method, the lowest concentrations of $\mathrm{INH}$ and PZA in the calibration curve were $0.25 \mu \mathrm{g} /$ $\mathrm{ml}$ and $1.25 \mu \mathrm{g} / \mathrm{ml}$ for INH and PZA respectively. The method reliably eliminated interfering material from plasma, yielding a recovery for INH and PZA that ranged from 100 to $106 \%$ and 99 to $105 \%$ respectively (Table 2 ).

\begin{tabular}{|c|c|c|c|c|c|}
\hline \multicolumn{2}{|c|}{ Added $(\mu \mathrm{g} / \mathrm{ml})$} & \multicolumn{2}{|c|}{$\begin{array}{l}\text { Estimated }(\mu \mathrm{g} / \mathrm{ml}) \\
(\text { Mean } \pm \mathrm{SD})\end{array}$} & \multicolumn{2}{|c|}{ Recovery (\%) } \\
\hline $\mathrm{INH}$ & PZA & INH & PZA & INH & PZA \\
\hline \multicolumn{2}{|c|}{ Baseline } & $\begin{array}{l}4.79 \pm \\
0.08\end{array}$ & $\begin{array}{l}44.11 \pm \\
0.90\end{array}$ & & \\
\hline 2.5 & 5 & $\begin{array}{l}7.43 \pm \\
0.03\end{array}$ & $\begin{array}{l}49.21 \pm \\
1.19\end{array}$ & 106 & 102 \\
\hline 5 & 10 & $\begin{array}{l}10.01 \pm \\
0.05\end{array}$ & $\begin{array}{l}54.35 \pm \\
1.25\end{array}$ & 104 & 102 \\
\hline \multicolumn{2}{|c|}{ Baseline } & \begin{tabular}{|l|}
$1.72 \pm$ \\
0.06 \\
\end{tabular} & $\begin{array}{l}21.42 \pm \\
0.75\end{array}$ & & \\
\hline 2.5 & 5 & \begin{tabular}{|l|}
$4.22 \pm$ \\
0.04 \\
\end{tabular} & $\begin{array}{l}26.38 \pm \\
0.67\end{array}$ & 100 & 99 \\
\hline 5 & 10 & \begin{tabular}{|l|}
$7.02 \pm$ \\
0.04
\end{tabular} & $\begin{array}{l}1.91 \pm \\
0.75\end{array}$ & 106 & 105 \\
\hline
\end{tabular}


The method described was applied for the determination of INH and PZA concentrations in plasma from six children receiving treatment with RMP, INH, PZA and EMB. These children received doses based on their body weight. The dose of $\mathrm{INH}$ ranged from 150 to $300 \mathrm{mg}$, while that of PZA ranged from 500 to $1000 \mathrm{mg}$. Figures 2 and 3 respectively present the mean plasma $\mathrm{INH}$ and PZA concentrations obtained in children at various time points after drug administration. The plasma concentrations of INH and PZA increased steadily and attained a peak level at about two hours. The mean plasma peak concentrations of $7.7 \mu \mathrm{g} / \mathrm{ml}$ and $44.1 \mu \mathrm{g} / \mathrm{ml}$ for INH and PZA respectively were obtained at two hours; thereafter the drug levels declined steadily. Thus the plasma concentrations of INH and PZA followed a typical pharmacokinetic pattern.

The mean plasma INH concentrations measured on days 1 and 30 in five plasma samples stored at $-20^{\circ} \mathrm{C}$ were 6.03 and $5.67 \mu \mathrm{g} / \mathrm{ml}$ respectively; the corresponding values for PZA were 32.45 and $31.35 \mu \mathrm{g} / \mathrm{ml}$ respectively. No degradation of INH and PZA in plasma occurred up to 30 days when stored at $-20^{\circ} \mathrm{C}$.

In conclusion, a sensitive, specific and validated method for quantitative simultaneous determination of INH and PZA in plasma is described. This rapid, accurate and reproducible method utilises a single step extraction. The chromatograms yield wellresolved peaks for INH and PZA with good intra- and inter-day precision. The easy sample preparation and small sample size makes this assay highly suitable for estimation of plasma concentrations of INH and PZA as part of pharmacokinetic studies or therapeutic drug monitoring in TB patients.

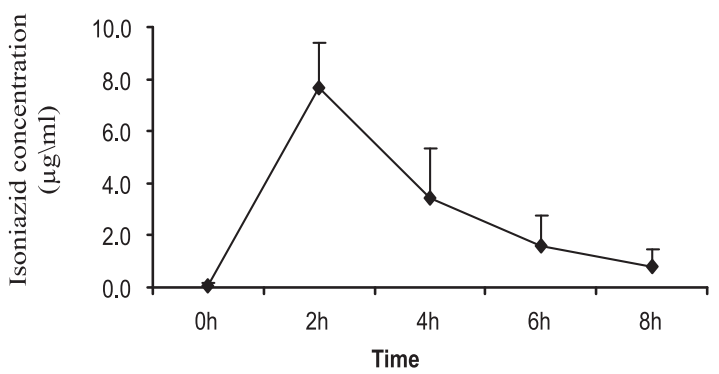

Figure 2. Mean plasma isoniazid concentrations in six children with tuberculosis Vertical bars represent standard deviation

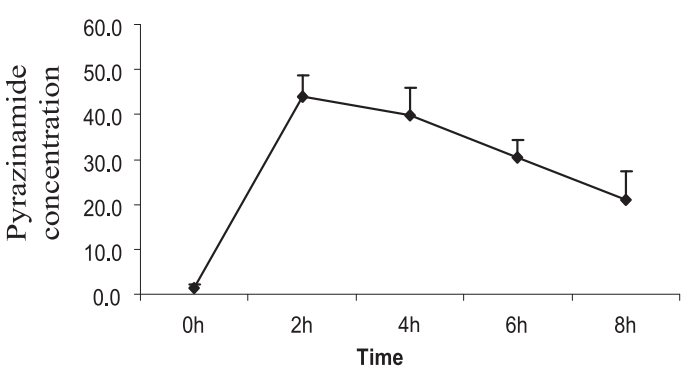

Figure 3. Mean plasma pyrazinamide concentrations in six children with tuberculosis

\section{REFERENCES}

1. Burman WJ, Gallicano K, Peloquin CA. Comparative pharmacokinetics and pharmacodynamics of the rifamycin antibacterials. Clin Pharmacokinet 2001;40:327-41.

2. Kimerling M, Phillips $P$, Patterson $P$, Hall M, Robinson CA, Dunlap NE. Low serum antimycobacterial drug levels in non-HIV-infected tuberculosis patients. Chest 1998;113:1178-83.

3. Um SW, Lee SW, Kwon SY et al. Low serum concentrations of anti-tuberculosis drugs and determinants of their serum levels. Int $\mathrm{J}$ Tuberc Lung Dis 2007;11:972-8.

4. Mclleron H, Wash P, Burger A, Norman J, Folb $\mathrm{PI}$, Smith P. Determinants of rifampicin, isoniazid, pyraznamide and ethambutol pharmacokinetics in a cohort of tuberculosis patients. Antimicrob Agents Chemother 2006;50:1170-7.

5. Tappero JW, Bradford WZ, Agerton TB et al. Serum concentrations of antimycobacterial drugs in patients with pulmonary tuberculosis in Botswana. Clin Infect Dis 2005;41:461-9.

6. Moussa LA, Khassouani CE, Soulaymani $R$ et al. Therapeutic isoniazid monitoring using a simple high performance liquid chromatographic method with ultraviolet detection. J Chromatogr B Analyt Techonol Biomed Life Sci 2002;766: 181-7.

7. Revankar $S N$, Desai $N D$, Vaidya $A B$, Bhatt $A D$, Anjaneyulu $B$. Determination of pyrazinamide in human by high performance liquid chromatography. J Postgrad Med 1994;40:7-9.

8. Chan $\mathrm{K}$, Wong $\mathrm{CL}$, Lok S. High-performance liquid chromatographic determination of pyrazinamide in cerebrospinal fluid and plasma in the rabbit. $J$ Chromatogr 1986;380:367-73. 
9. Mehmedagic A, Verite $P$, Menager $S$ et al. Determination of pyrazinamide and its main metabolites in rat urine by high-performance liquid chromatography. J Chromatogr B Biomed Sci Appl 1997;695:365-72.

10. Kraemer HJ, Feltkamp U, Beithaupt HB. Quantification of pyrazinamide and its metabolites in plasma by ionic-pair high-performance liquid chromatography. Implications for the separation mechanism. J Chromatogr B Biomed Sci Appl 1998;706:319-28.

11. Conte JE Jr, Lin E, Zurlinden E. High-performance liquid chromatographic determination of pyrazinamide in human plasma, brochoalveolar lavage fluid, and alveolar cells. J Chromatogr Sci 2000;38:33-7.

12. Khuhawar MY, Rind FM. Liquid chromatographic determination of isoniazid, pyrazinamide and rifampicin from pharmaceutical preparations and blood. J Chromatogr B Analyt Techonol Biomed Life Sci 2002;766:357-63.
13. Simth PJ, van Dyk J, Fredericks A. Determination of rifampicin, isoniazid and pyrazinamide by high performance liquid chromatography after their simultaneous extraction from plasma. Int J Tuberc Lung Dis 1999;3:S351-2.

14. Song SH, Jun SH, Park KU et al. Simultaneous determination of first-line anti-tuberculosis drugs and their major metabolic ratios by liquid chromatography/tandem mass spectrometry. Rapid Commun Mass Spectrom 2007;21:1331-8.

15. Aymard G, Legrand M, Trichereau N, Diquet B. Determination of tweleve antiretroviral agents in human plasma sample using reversed-phase high performance liquid chromatography. J Chromatogr B 2000;744:227-40. 